\title{
Diabetes, bone and glucose-lowering agents: clinical outcomes
}

\author{
Ann V. Schwartz 1
}

Received: 5 January 2017 / Accepted: 17 March 2017 /Published online: 27 April 2017

(C) Springer-Verlag Berlin Heidelberg 2017

\begin{abstract}
Older adults with diabetes are at higher risk of fracture and of complications resulting from a fracture. Hence, fracture risk reduction is an important goal in diabetes management. This review is one of a pair discussing the relationship between diabetes, bone and glucose-lowering agents; an accompanying review is provided in this issue of Diabetologia by Beata Lecka-Czernik (DOI 10.1007/s00125-017-4269-4). Specifically, this review discusses the challenges of accurate fracture risk assessment in diabetes. Standard tools for risk assessment can be used to predict fracture but clinicians need to be aware of the tendency for the bone mineral density Tscore and the fracture risk assessment tool (FRAX) to underestimate risk in those with diabetes. Diabetes duration, complications and poor glycaemic control are useful clinical markers of increased fracture risk. Glucose-lowering agents may also affect fracture risk, independent of their effects on glycaemic control, as seen with the negative skeletal effects of the thiazolidinediones; in this review, the potential effects of glucose-lowering medications on fracture risk are discussed. Finally, the current understanding of effective fracture prevention in older adults with diabetes is reviewed.
\end{abstract}

Keywords Bone mineral density · Diabetes mellitus . Fracture $\cdot$ Fracture prevention · Glucose-lowering agents · Review $\cdot$ Risk assessment

Electronic supplementary material The online version of this article (doi:10.1007/s00125-017-4283-6) contains a slideset of the figures for download, which is available to authorised users.

Ann V. Schwartz

aschwartz@psg.ucsf.edu

1 Department of Epidemiology and Biostatistics, University of California San Francisco, Box 0560, San Francisco, CA 94143, USA

$\begin{array}{ll}\text { Abbreviations } \\ \text { 25(OH)D } & \begin{array}{l}\text { 25-hydroxyvitamin D } \\ \text { ACCORD }\end{array} \\ & \begin{array}{l}\text { Action to Control Cardiovascular Risk in } \\ \text { Diabetes }\end{array} \\ \text { ADOPT } & \text { A Diabetes Outcome Progression Trial } \\ \text { BMD } & \text { Bone mineral density } \\ \text { DPP-4 } & \text { Dipeptidyl peptidase-4 } \\ \text { FRAX } & \text { Fracture risk assessment tool } \\ \text { GLP-1 } & \text { Glucagon-like peptide-1 } \\ \text { SGLT2 } & \text { Sodium-glucose cotransporter } \\ \text { TZD } & \text { Thiazolidinediones }\end{array}$

\section{Introduction}

There is a growing appreciation that increased fracture risk is a consequence of diabetes. In type 1 diabetes, hip fracture risk is four to six times higher compared with those without diabetes $[1,2]$. For type 2 diabetes, the increased risk is more modest, estimated at $1.34(95 \%$ CI $1.19,1.51)$ in a recent metaanalysis of 12 studies [2]. Risk of non-hip fractures also appears to be increased in type $1[3]$ and type $2[4,5]$ diabetes. And, the realisation that thiazolidinediones (TZDs) increase fracture risk [6] has resulted in greater awareness that glucoselowering agents may affect fracture, independent of any effects of diabetes.

Fractures cause substantial increased morbidity and mortality in older adults [7] and these consequences appear to be worse in those with diabetes [8-11]. Maintenance of adequate glycaemic control may be more difficult in the months following a fracture [12]. Effective fracture prevention is thus an important goal for older individuals with diabetes. However, fracture risk assessment and prevention both present particular challenges in this population. Standard risk assessment tools tend to underestimate risk in older adults with diabetes and 
fracture prevention guidelines lack specific recommendations for those with diabetes.

The aim of this review is to summarise our current understanding of the impact of diabetes and glucose-lowering agents on fracture risk and discuss the issues that are specific to fracture risk assessment and prevention in individuals with diabetes.

\section{Fracture risk assessment in diabetes}

Lower bone mineral density (BMD), particularly at the hip, is strongly associated with fracture incidence and is central to fracture risk assessment in older adults [13]. BMD is often expressed as a T-score, the number of standard deviations above or below the average BMD for a healthy 30-year-old adult. Absolute fracture risk can be calculated using the fracture risk assessment tool (FRAX), which incorporates clinical risk factors in addition to BMD [14]. Many clinical guidelines for fracture prevention use the BMD T-score and/or FRAX to identify higher risk individuals and to specify thresholds for consideration of pharmacological therapy [15-17]. However, type 2 diabetes is associated with an average or even high BMD compared with those who do not have diabetes $[18,19]$. Type 1 diabetes is characterised by lower BMD, but the reductions are only modest and do not account for the substantially elevated fracture risk with this condition [20]. Thus, the bone in diabetes appears to have reduced strength for a given BMD in both type 1 and type 2 diabetes and, as a result, the standard tools (BMD T-score and FRAX) tend to underestimate fracture risk in individuals with diabetes, presenting a challenge for clinicians.

BMD T-score In a study combining data from three US cohorts, femoral neck BMD T-score underestimated risk of hip and non-spine fractures in those with type 2 diabetes [21]. Fig. 1a illustrates the relationship between hip fracture and femoral neck BMD T-score in older women; in women with and without diabetes, lower BMD T-score predicted increased fracture risk. However, at any given BMD T-score, women with diabetes had a higher fracture risk, and, at any given fracture risk, women with diabetes had a higher BMD T-score, compared with women without diabetes. On average, the difference in T-score between women with and without diabetes who had the same hip fracture risk was 0.6. Fig. 1b illustrates the same relationship in men with and without diabetes, indicating that BMD T-score also tends to under-estimate hip fracture risk in men. Thus, the standard BMD T-score thresholds for considering pharmacological therapy for osteoporosis are probably too low for individuals with diabetes. Higher fracture risk at a given BMD also provides evidence that diabetes increases bone fragility through mechanisms other than bone loss, as discussed in the accompanying review by Beata LeckaCzernik in this issue of Diabetologia [22].

BMD also underestimates fracture risk in individuals with type 1 diabetes. A meta-analysis reported that BMD Z-score (a comparison with an age- and sex-matched reference population) was $-0.37 \pm 0.16$ at the hip and $-0.22 \pm 0.01$ at the spine for those with type 1 diabetes [20]. The predicted increase in hip fracture risk, based on the reduced hip BMD, was 1.42; however, the actual increased relative risk was 6.94 . Hence, we can surmise that BMD measurements (and FRAX) tend to underestimate fracture risk in type 1 diabetes. However, without direct studies on fracture prediction in type 1 diabetes, it is not possible to quantify the degree of underestimation.

FRAX FRAX is a widely used fracture risk assessment tool that incorporates femoral neck BMD T-score with additional risk factors: age, sex, BMI, history of fracture, parental history of hip fracture, current smoking status, alcohol consumption, rheumatoid arthritis and glucocorticoid use. Diabetes is not currently included in the FRAX algorithm. Similar to femoral neck BMD T-score, FRAX may be used to predict fracture risk in those with diabetes but it underestimates the risk of hip and major osteoporotic fractures (hip, vertebral, forearm and humerus) in these individuals [21, 23]. Interestingly, when the association between the FRAX-incorporated risk factors and fracture risk was assessed in a large cohort in Manitoba, Canada, each risk factor was found to have a similar association with fracture risk in those with and without diabetes, except for age and parental history of hip fracture [24]; underestimation of hip fracture risk using FRAX was greater in younger (40-69 years) compared with older study participants ( $\geq 70$ years).

The FRAX algorithm may be updated in the future to include diabetes as a risk factor [25]. Until then, however, when using the current algorithm, clinicians should be aware of the tendency for it to underestimate fracture risk in diabetes. Possible options to provide a crude adjustment of the FRAX score for individuals with type 2 diabetes include indicating 'rheumatoid arthritis' as a risk factor or reducing the femoral neck BMD T-score by 0.5 [26].

\section{Diabetes-specific risk factors for fracture}

In addition to the standard risk factors for fracture discussed above, there are factors specific to diabetes that can inform risk assessment. Substantial evidence has identified diabetes duration and insulin use (see 'Glucose-lowering agents and fracture risk' section, below) as risk factors for fracture in type 2 diabetes. In addition, the presence of complications and the level of glycaemic control appear to be risk factors. 
Fig. 1 Femoral neck BMD Tscore and 10 year fracture risk in (a) women and (b) men at 75 years of age by diabetes and insulin use status. Solid line, no diabetes; red dashed line, diabetes without insulin use; blue dashed line, diabetes with insulin use. Adapted with permission from Schwartz et al [21]

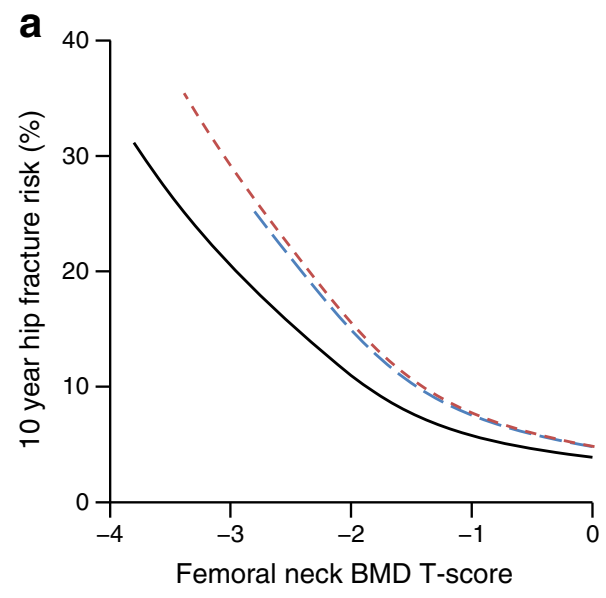

Furthermore, weight loss is an important component of diabetes management but is also associated with fracture risk.

Diabetes duration In type 2 diabetes, duration of disease is associated with greater risk of fracture [27-35]. In a cohort of women, aged $\geq 40$ years from Manitoba, Canada, diabetes duration was associated with higher risk of hip and major osteoporotic (hip, clinical vertebral, forearm, humerus) fractures (Fig. 2) [34]. This relationship persisted even following adjustment for insulin use. Fracture risk was compared in those without diabetes, with newly diagnosed diabetes, $<5$ years diabetes duration, 5-10 years diabetes duration and $>10$ years diabetes duration. Risk of major osteoporotic fracture was elevated in those with $>10$ years

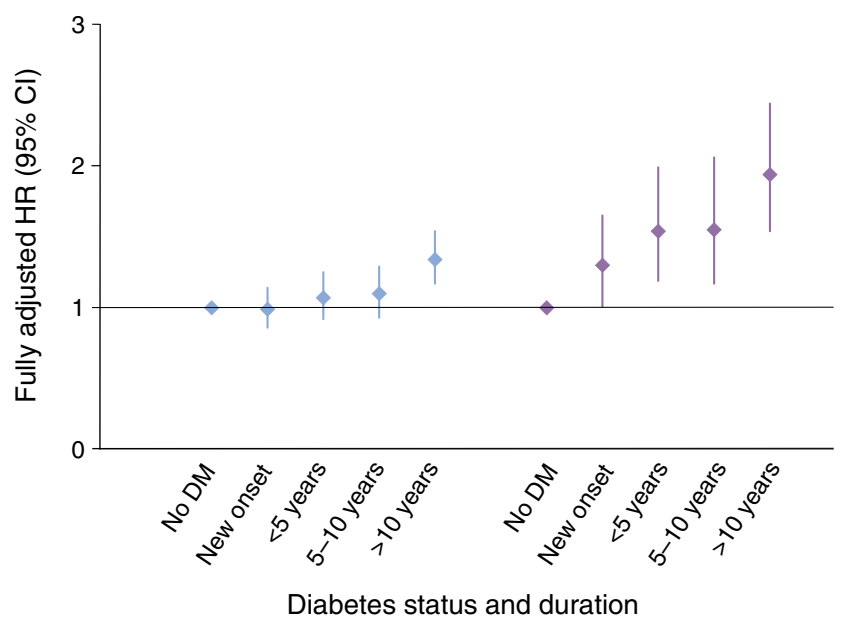

Fig. 2 Duration of diabetes (DM) and risk of major osteoporotic fractures (blue) and hip fractures (purple) among 57,938 women age $\geq 40$ years in the Manitoba BMD cohort, including 8840 with diabetes ascertained from health services records. Of those with ascertained diabetes, exclusion of 207 (2.3\%) women with presumptive type 1 diabetes did not materially alter the magnitude or statistical significance of results. Models were adjusted for BMD-based FRAX scores (which included age), burden of comorbidity, history of falls, prescription of osteoporosis treatments and insulin therapy. Adapted from Majumdar et al [34] diabetes duration compared with those without diabetes, whereas hip fracture was increased in all women with diabetes regardless of duration. Hip fracture risk was 1.94 $(95 \%$ CI $1.54,2.44)$ in those with $>10$ years diabetes duration compared with those without diabetes when adjusted for FRAX, comorbidities, history of falls, prescription of osteoporosis treatments, and insulin therapy. This study and others indicate that particular attention should be given to consideration of fracture prevention in older adults with diabetes duration of more than 10 years.

Presence of complications Diabetes-related complications, particularly multiple complications, are associated with higher risk of fracture [30, 31, 36-38]. Complications may reduce bone strength or increase falls, leading to more frequent fractures. The presence of complications may also be a marker for other conditions that increase fracture risk, such as higher levels of advanced glycation end-products [39] or compromised microvasculature in the bone $[22,40]$.

Glycaemic control Optimal levels of glycaemic control for fracture and fall prevention are not defined. However, achieving lower $\mathrm{HbA}_{1 \mathrm{c}}$ levels and, subsequently, preventing the onset of complications may have beneficial effects on bone and risk of falls. On the other hand, lower $\mathrm{HbA}_{1 \mathrm{c}}$ levels increase the frequency of hypoglycaemic episodes, which are associated with falls and fractures [41-43]. In the Action to Control Cardiovascular Risk in Diabetes (ACCORD) trial, fracture rates (HR 1.04 [95\% CI 0.86, 1.27]) and fall rates (rate ratio 1.10 [95\% CI 0.84, 1.43]) did not differ between intensive and standard glycaemic control groups [44]. The median level of $\mathrm{HbA}_{1 \mathrm{c}}$ achieved was $6.4 \%(46.4 \mathrm{mmol} / \mathrm{mol})$ in the intensive group and $7.5 \%(58.5 \mathrm{mmol} / \mathrm{mol})$ in the standard glycaemic control group [45]. While intensive and standard glycaemic control do not have substantially different effects on fall rates and fractures, ACCORD did not address the possible effects 
of poor glycaemic control on these factors. Evidence from longitudinal observational studies indicates that those with poor glycaemic control $\left(\mathrm{HbA}_{1 \mathrm{c}}>8 \%[>63.9 \mathrm{mmol} / \mathrm{mol}]\right)$ are at higher risk of fracture compared with those with lower $\mathrm{HbA}_{1 \mathrm{c}}$ levels [46-49].

Weight loss In overweight and obese individuals with type 2 diabetes, moderate weight loss is recommended for improvements in glycaemic control and to reduce the need for glucose-lowering medications. However, weight loss is associated with bone loss and increased fracture risk in broader populations of older adults [50]. In the Action for Health in Diabetes (Look AHEAD) trial, which was conducted in overweight and obese participants with diabetes, a lifestyle intervention that achieved weight loss was also associated with modest bone loss at the hip [51]. Total fractures were not increased but fractures associated with frailty were more frequent in the weight loss group [52].

\section{Glucose-lowering agents and fracture risk}

TZDs As discussed in the accompanying review by Beata Lecka-Czernik [22], preclinical studies have identified negative effects of TZDs on bone, including reduced bone formation and increased bone resorption [53]. Clinically, evidence from adverse event reporting in randomised clinical trials has established that TZDs increase fracture risk in women. The first report of increased fracture risk came from the A Diabetes Outcome Progression Trial (ADOPT), which compared the TZD rosiglitazone with metformin or a sulfonylurea as first-line treatment for newly diagnosed diabetes [54]. Subsequent meta-analyses of RCTs of rosiglitazone and pioglitazone elaborate on these initial findings $[6,55]$. In the latest meta-analysis, which included 22 RCTs, the risk of fracture was approximately doubled in women using a TZD (OR 1.94 [95\% CI 1.60, 2.35]) but was not increased in men (OR 1.02 [95\% CI 0.83, 1.27]) [6]. This increased fracture risk in women was reported for both pioglitazone (OR 1.73 [95\%CI 1.18, 2.55]) and rosiglitazone (OR 2.01 [95\% CI 1.61, 2.51]). The reasons for this sex difference in the effect of TZDs on fracture risk are not understood. However, in ADOPT, rosiglitazone had similar effects on fracture risk in preand postmenopausal women, suggesting that differences in oestrogen levels are not responsible for the increase in fracture risk in women [54].

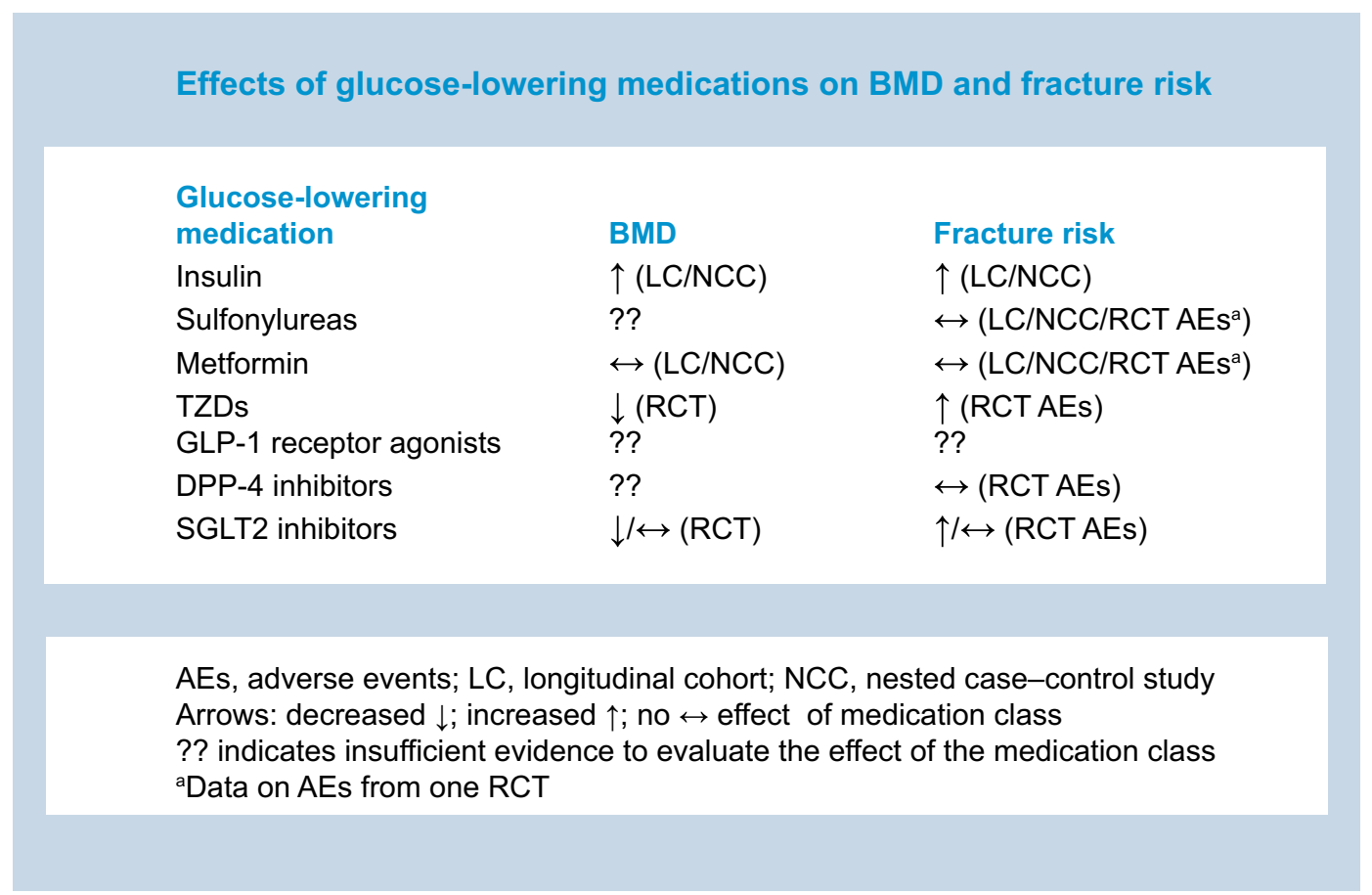


Consistent with increased fracture risk, TZD use results in more rapid bone loss. A meta-analysis of RCTs with median TZD treatment duration of 48 weeks reported a difference of $-1.0 \%(95 \%$ CI $-1.4,-0.6)$ for total hip BMD and $-1.1 \%$ (95\% CI $-1.6,-0.7)$ for lumbar spine BMD, comparing TZD-treated and control groups [56]. However, this degree of bone loss does not fully account for the observed increase in fracture risk, suggesting that other aspects of bone strength are compromised by TZD use. In addition, the median duration of the trials included in this meta-analysis was less than a year; it is not known if bone loss plateaus after this time or if this more rapid loss continues with extended TZD use. The same authors also conducted a meta-analysis of the effects of TZD use on markers of bone turnover but found no consistent pattern [56].

Limited evidence is available on the persistence of the effect of TZDs on the skeleton after discontinuation of use. In a meta-analysis of five RCTs, bone loss after TZD discontinuation was similar in those originally assigned to TZD treatment compared with the control group [56]. In the ACCORD study, fracture risk was reduced after TZD discontinuation and after 2 years it was similar to the risk in women who had never used a TZD during ACCORD [57].

The realisation that TZDs increase fracture risk has resulted in a new awareness of the potential for glucose-lowering agents to affect skeletal health. Fracture events are now generally reported as a distinct category of adverse events for new glucose-lowering medications. Consequently, data are available for fractures reported as adverse events in randomised clinical trials of other glucose-lowering agents, such as incretin-based medications and sodium-glucose cotransporter 2 (SGLT2) inhibitors, as discussed below.

Incretin-based medications The incretin-based medications include glucagon-like peptide-1 (GLP-1) receptor agonists and dipeptidyl peptidase-4 (DPP-4) inhibitors. As discussed in the accompanying review [22], incretins are involved in the regulation of bone turnover. Animal studies have revealed positive effects of GLP-1 receptor agonists on bone but have not identified consistent effects of DPP-4 inhibitors [53]. An initial meta-analysis that included 28 randomised clinical trials of DPP-4 inhibitor therapies reported a protective effect on fractures, identified through serious adverse event reports [58]. However, this appears to have been a chance finding as subsequent meta-analyses, incorporating additional RCTs, found no evidence of an effect of DPP-4 inhibitor therapy on fractures [59, 60]. For example, the largest published meta-analysis included 62 RCTs of DPP-4 inhibitor therapies with 722 fractures and reported a relative risk of 0.95 (95\% CI
$0.83,1.10)$ for fractures in participants using DPP-4 inhibitors compared with the control group [59].

The evidence available for the effects of GLP-1 receptor agonists on fracture risk is more limited. The largest metaanalysis of RCTs included only 14 RCTs and a total of 38 fractures [61]. There was no evidence of an effect on fracture risk (OR 1.05 [95\% CI 0.59, 1.87]) for these medications as a class. However, in separate analyses, liraglutide was associated with decreased fracture risk (OR 0.38 [95\% CI 0.17, 0.87]) and exenatide was associated with increased risk (OR 2.09 [95\% CI 1.03, 4.21]). This observed difference in fracture effects lacks a clear physiological basis and may be a chance finding. In two recent large observational studies, current GLP-1 receptor agonist use was not associated with fracture risk $[62,63]$. Additional studies are needed to clarify the effects of the GLP-1 receptor agonists on fracture risk.

SGLT2 inhibitors The SGLT2 inhibitors reduce blood glucose levels by inhibiting tubular reabsorption of glucose and thus increasing urinary excretion [64]. Concomitant increases in serum phosphate may lead to changes in parathyroid hormone (PTH) and fibroblast growth factor 23 (FGF23) that could affect bone metabolism. SGLT2 inhibitors also induce weight loss, which is associated with bone loss and fracture risk [50]. Further, as an additional mechanism, a greater frequency of intravascular volume depletion with SGLT2 inhibitor use could increase falls, leading to greater fracture risk. Clinical studies into the effects of SGLT2 inhibitors on bone and fracture risk have produced mixed results. A 50-week trial of dapagliflozin found no increase in bone loss, compared with placebo [65]. In contrast, a 104-week study of canagliflozin found increased bone loss at the total hip $(-1.2 \%$ [95\% CI $-1.9,-0.8]$ ), compared with placebo [66]. A rigorous metaanalysis of nine RCTs of canagliflozin took the additional step of reviewing all reports of fractures, since adverse event reports are susceptible to misclassification of fracture outcomes, which, in a blinded trial, may tend to attenuate any actual differences [67].

In their analysis, the investigators found an increased fracture risk for canagliflozin compared with placebo (1.32 [95\% CI 1.00, 1.74]). The result was driven by increased fracture risk in the CANagliflozin cardioVascular Assessment Study (CANVAS) that included individuals at higher risk of cardiovascular disease. In contrast, a large trial of empagliflozin reported no difference in fracture (identified as serious adverse events) compared with placebo [68]. Thus, further study is required to determine whether there are differences in fracture effects within the SGLT2 inhibitor class of medications. 
Sulfonylureas and metformin The effects of sulfonylureas and metformin on fractures are difficult to assess since these medications are generally not tested in RCTs. Sulfonylureas are not thought to affect bone directly but may increase fracture risk via inducing higher rates of hypoglycaemic episodes. In contrast, animal studies suggest a positive effect of metformin on bone metabolism [22]. A comparison of fracture risk between randomly allocated treatment with metformin and the sulfonylurea glibenclamide (known as glyburide in the USA and Canada) was reported in the ADOPT trial [54]. Fracture risk for those using metformin or glibenclamide as first-line therapy was found to be similar, despite more frequent hypoglycaemia in the glibenclamide arm. A review in 2013 concluded that there was a lack of evidence for increased fracture risk with sulfonylurea use but that higher quality studies in older adults were needed to definitively address this question [69]. Since then, additional observational studies have reported on sulfonylureas and fracture risk with some [70-72], but not others [41, 73-75], reporting increased risk. In contrast, some [41, 74, 76], although not all [70, 73, 77], observational studies of metformin and fracture risk have reported reduced fracture risk. Notably, individuals assigned to metformin therapy tend to have fewer risk factors for fracture than those assigned to a sulfonylurea [73] and these differences are difficult to account for in observational studies.

Insulin Individuals with type 2 diabetes using insulin therapy appear to be at increased risk of fracture, based on observational studies [70, 74, 77-79]. Insulin treatment is not believed to have a negative effect on bone strength; rather insulin is likely to be anabolic for bone [80]. Instead, insulin treatment may have direct negative effects via an increase in hypoglycaemia and, hence, in falls [81]. In addition, the need for insulin treatment is probably a marker of poorer health in older individuals, which contributes to fracture risk.

\section{Fracture prevention in individuals with diabetes}

Preventing fractures is a crucial goal in older adults with diabetes. For those with higher fracture risk, fracture prevention guidelines that are specific for individuals with diabetes include avoidance of TZDs and SGLT2 inhibitors [82]. In addition, maintenance of good glycaemic control may contribute to reduced fracture risk. However, it is evident that further research is required to fully elucidate the optimal management of fracture risk in diabetes. Guidelines for fracture prevention that are appropriate for older adults in general delineate strategies that are also applicable to those with diabetes, including fall prevention, sufficient vitamin $\mathrm{D}$ and calcium intake, weight-bearing exercise, tobacco cessation and limiting alcohol intake [15].
Vitamin D Vitamin D levels tend to be lower in those with type 1 or type 2 diabetes [83,84] and vitamin D is generally acknowledged as being important for bone health [85]. Vitamin D in combination with calcium supplementation provides a modest reduction in fracture risk [86]. Serum 25-hydroxyvitamin $\mathrm{D}(25(\mathrm{OH}) \mathrm{D})$ levels $\leq 30 \mathrm{nmol} / \mathrm{l}(12 \mathrm{ng} / \mathrm{ml})$ are considered deficient in the context of bone health, but there is controversy regarding the target for sufficient serum levels [87]. High levels of serum $25(\mathrm{OH}) \mathrm{D}$, in the range of $125-190 \mathrm{nmol} / 1(50-75 \mathrm{ng} / \mathrm{ml})$, are associated with adverse outcomes in observational studies, including higher mortality and increased rates of cardiovascular disease [85]. Guidelines for dietary intake (from food and supplements) to achieve sufficient levels of vitamin D for skeletal health benefits in older adults are in the range of $600-1000 \mathrm{IU} /$ day $[15,85]$. Other health benefits of vitamin $\mathrm{D}$, including prevention of diabetes, have been hypothesised based on observational studies but have not yet been proven [85]. Randomised trials of vitamin D supplementation are currently underway and should provide greater clarity on non-skeletal health effects in the next few years.

Pharmacological therapies For those at higher risk of fracture, effective pharmacological interventions are available [88]. Current guidelines for older adults recommend consideration of pharmacological therapy after a vertebral or hip fracture, an event that indicates a high risk of subsequent fracture [15]. The occurrence of these fractures in an individual with diabetes is also a signal of higher risk of a subsequent fracture and would warrant consideration of pharmacological therapy [24]. With regard to appropriate management after fractures at other sites in diabetes, the best approach is dependent on assessment of overall fracture risk. As discussed earlier, in those with type 2 diabetes, BMD T-score and FRAX scores can identify those at highest fracture risk, with the caveat that these methods tend to underestimate risk in diabetes. The usefulness of BMD testing and FRAX for type 1 diabetes has not been extensively studied and, thus, is yet to be established. As with type 2 diabetes, it seems likely that low BMD will predict fracture in this population but will tend to underestimate risk.

Guidelines for pharmacological therapy to prevent fracture have been established based on large randomised clinical trials in the broader population of postmenopausal women with low BMD and/or prevalent fractures. These results are currently the best guide for use of osteoporosis therapies in individuals with diabetes. Concern has been expressed that bisphosphonates and other anti-resorptive therapies may not be effective in those with diabetes since the bone in diabetes is characterised by reduced bone formation [89]. Specific evidence regarding response to this type of treatment in those with diabetes is limited but, to date, post hoc analyses of larger trials of bisphosphonates and raloxifene have found that treatment 
effects on bone turnover, BMD and fracture are similar in women with and without diabetes [90-93]. Observational studies have also reported similar efficacy of bisphosphonates [94, 95] and teriparatide [96] for fracture prevention in those with and without diabetes, and similar anti-fracture efficacy for bisphosphonates in type 1 and type 2 diabetes [94]. These post hoc analyses and observational studies are generally limited to those with osteoporosis. The efficacy of these therapies in individuals with diabetes who have elevated fracture risk but BMD levels above the standard threshold defining osteoporosis is not known.

In general, pharmacological therapy for osteoporosis is not used to its full potential in the osteoporotic population and its use appears to be even lower among those with diabetes [17, 97]. In part, this failure to fully make use of osteoporosis therapy, even after a hip or vertebral fracture, is attributed to concerns regarding the occurrence of atypical femur fractures and osteonecrosis of the jaw, which is associated with the use of bisphosphonates and other anti-resorptive therapies [98, 99]. However, the benefits of these therapies on fracture prevention substantially outweigh the risks of these rare events, estimated at less than one event for every 100 fractures prevented [88]. It is difficult to determine whether these rare adverse events are more common in those with diabetes and evidence to date has been inconsistent [99, 100]. However, even if the risk of these events is higher in those with diabetes, the events are sufficiently rare that fracture benefits of antiresorptive therapies would still strongly outweigh risks among those with diabetes.

\section{Conclusion}

Increased fracture risk is a consequence of diabetes and fracture prevention is an important goal for the clinical management of diabetes in older adults. BMD T-score and FRAX are standard tools for risk assessment that are also useful to assess fracture risk in those with diabetes. However, both of these methods tend to underestimate risk in individuals with diabetes. Other diabetes-specific risk factors can help to identify high-risk individuals, including diabetes duration, presence of complications and poor glycaemic control. Most glucoselowering medications appear to have a neutral effect on fracture risk, but TZDs should be avoided in individuals at higher risk of fracture. Caution is also currently warranted with SGLT2 inhibitors in these individuals. General guidelines for fracture prevention, formulated for the broader population of older adults, are also applicable to those with diabetes, including use of pharmacological therapy in individuals with high fracture risk. However, further studies are required to determine the optimal management strategies for fracture prevention in diabetes.
Funding This research received no specific grant from any funding agency in the public, commercial or not-for-profit sectors.

Duality of interest AVS served as a consultant for Amgen and Janssen Pharmaceuticals Inc.

Contribution statement AVS was the sole contributor to this paper.

\section{References}

1. Shah VN, Shah CS, Snell-Bergeon JK (2015) Type 1 diabetes and risk of fracture: meta-analysis and review of the literature. Diabet Med 32:1134-1142

2. Fan Y, Wei F, Lang Y, Liu Y (2016) Diabetes mellitus and risk of hip fractures: a meta-analysis. Osteoporos Int 27:219-228

3. Weber DR, Haynes K, Leonard MB, Willi SM, Denburg MR (2015) Type 1 diabetes is associated with an increased risk of fracture across the life span: a population-based cohort study using the health improvement network (THIN). Diabetes Care 38:1913-1920

4. Bonds DE, Larson JC, Schwartz AV et al (2006) Risk of fracture in women with type 2 diabetes: the Women's Health Initiative Observational Study. J Clin Endocrinol Metab 91:3404-3410

5. Janghorbani M, Van Dam RM, Willett WC, Hu FB (2007) Systematic review of type 1 and type 2 diabetes mellitus and risk of fracture. Am J Epidemiol 166:495-505

6. Zhu ZN, Jiang YF, Ding T (2014) Risk of fracture with thiazolidinediones: an updated meta-analysis of randomized clinical trials. Bone 68:115-123

7. Cauley JA (2013) Public health impact of osteoporosis. J Gerontol A Biol Sci Med Sci 68:1243-1251

8. Norris R, Parker M (2011) Diabetes mellitus and hip fracture: a study of 5966 cases. Injury 42:1313-1316

9. Hu F, Jiang C, Shen J, Tang P, Wang Y (2012) Preoperative predictors for mortality following hip fracture surgery: a systematic review and meta-analysis. Injury 43:676-685

10. Liao CC, Lin CS, Shih CC et al (2014) Increased risk of fracture and postfracture adverse events in patients with diabetes: two nationwide population-based retrospective cohort studies. Diabetes Care 37:2246-2252

11. Zura R, Xiong Z, Einhorn T et al (2016) Epidemiology of fracture nonunion in 18 human bones. JAMA Surg 151:e162775

12. Lee SY, Park MS, Kwon SS, Sung KH, Jung HS, Lee KM (2016) Influence of ankle fracture surgery on glycemic control in patients with diabetes. BMC Musculoskelet Disord 17:137

13. Marshall D, Johnell O, Wedel H (1996) Meta-analysis of how well measures of bone mineral density predict occurrence of osteoporotic fractures. BMJ 312:1254-1259

14. FRAX fracture risk assessment tool. Available from http://shef.ac. uk/FRAX/tool.jsp. Accessed 10 Mar 2017

15. Cosman F, de Beur SJ, LeBoff MS et al (2014) Clinician's guide to prevention and treatment of osteoporosis. Osteoporos Int 25: 2359-2381

16. Compston J, Bowring C, Cooper A et al (2013) Diagnosis and management of osteoporosis in postmenopausal women and older men in the UK: National Osteoporosis Guideline Group (NOGG) update 2013. Maturitas 75:392-396

17. Hernlund E, Svedbom A, Ivergard M et al (2013) Osteoporosis in the European Union: medical management, epidemiology and economic burden. A report prepared in collaboration with the International Osteoporosis Foundation (IOF) and the European Federation of Pharmaceutical Industry Associations (EFPIA). Arch Osteoporos 8:136 
18. Ma L, Oei L, Jiang L et al (2012) Association between bone mineral density and type 2 diabetes mellitus: a meta-analysis of observational studies. Eur J Epidemiol 27:319-332

19. Ahmad OS, Leong A, Miller JA et al (2016) A Mendelian randomization study of the effect of type-2 diabetes and glycemic traits on bone mineral density. J Bone Miner Res. doi:10.1002/ jbmr.3063

20. Vestergaard P (2007) Discrepancies in bone mineral density and fracture risk in patients with type 1 and type 2 diabetes - a metaanalysis. Osteoporos Int 18:427-444

21. Schwartz AV, Vittinghoff E, Bauer DC et al (2011) Association of BMD and FRAX score with risk of fracture in older adults with type 2 diabetes. JAMA 305:2184-2192

22. Lecka-Czernik B (2017) Diabetes, bone and glucose-lowering agents: basic biology. Diabetologia. doi:10.1007/s00125-0174269-4

23. Giangregorio LM, Leslie WD, Lix LM et al (2012) FRAX underestimates fracture risk in patients with diabetes. J Bone Miner Res 27:301-308

24. Leslie WD, Morin SN, Lix LM, Majumdar SR (2014) Does diabetes modify the effect of FRAX risk factors for predicting major osteoporotic and hip fracture? Osteoporos Int 25:2817-2824

25. Leslie WD, Rubin MR, Schwartz AV, Kanis JA (2012) Type 2 diabetes and bone. J Bone Miner Res 27:2231-2237

26. Schacter GI, Leslie WD (2016) DXA-based measurements in diabetes: can they predict fracture risk? Calcif Tissue Int 100:150-164

27. Schwartz AV, Sellmeyer DE, Ensrud KE et al (2001) Older women with diabetes have an increased risk of fracture: a prospective study. J Clin Endocrinol Metab 86:32-38

28. Nicodemus KK, Folsom AR (2001) Type 1 and type 2 diabetes and incident hip fractures in postmenopausal women. Diabetes Care 24:1192-1197

29. Forsen L, Meyer HE, Midthjell K, Edna TH (1999) Diabetes mellitus and the incidence of hip fracture: results from the NordTrondelag Health Survey. Diabetologia 42:920-925

30. Ivers RQ, Cumming RG, Mitchell P, Peduto AJ (2001) Diabetes and risk of fracture: The Blue Mountains Eye Study. Diabetes Care 24:1198-1203

31. Melton LJ 3rd, Leibson CL, Achenbach SJ, Therneau TM, Khosla S (2008) Fracture risk in type 2 diabetes: update of a populationbased study. J Bone Miner Res 23:1334-1342

32. Janghorbani M, Feskanich D, Willett WC, Hu F (2006) Prospective study of diabetes and risk of hip fracture: the Nurses' Health Study. Diabetes Care 29:1573-1578

33. Hothersall EJ, Livingstone SJ, Looker HC et al (2014) Contemporary risk of hip fracture in type 1 and type 2 diabetes: a national registry study from Scotland. J Bone Miner Res 29: 1054-1060

34. Majumdar SR, Leslie WD, Lix LM et al (2016) Longer duration of diabetes strongly impacts fracture risk assessment: the Manitoba BMD cohort. J Clin Endocrinol Metab 101:4489-4496

35. Koh WP, Wang R, Ang LW, Heng D, Yuan JM, Yu MC (2010) Diabetes and risk of hip fracture in the Singapore Chinese Health Study. Diabetes Care 33:1766-1770

36. Strotmeyer ES, Cauley JA, Schwartz AV et al (2005) Nontraumatic fracture risk with diabetes mellitus and impaired fasting glucose in older white and black adults: the health, aging, and body composition study. Arch Intern Med 165:1612-1617

37. Viegas M, Costa C, Lopes A, Griz L, Medeiro MA, Bandeira F (2011) Prevalence of osteoporosis and vertebral fractures in postmenopausal women with type 2 diabetes mellitus and their relationship with duration of the disease and chronic complications. J Diabetes Complicat 25:216-221

38. Strotmeyer ES, Kamineni A, Cauley JA et al (2011) Potential explanatory factors for higher incident hip fracture risk in older diabetic adults. Curr Gerontol Geriatr Res 2011:979270
39. Schwartz AV, Garnero P, Hillier TA et al (2009) Pentosidine and increased fracture risk in older adults with type 2 diabetes. J Clin Endocrinol Metab 94:2380-2386

40. Carulli C, Innocenti M, Brandi ML (2013) Bone vascularization in normal and disease conditions. Front Endocrinol (Lausanne) 4: 106

41. Vestergaard P, Rejnmark L, Mosekilde L (2005) Relative fracture risk in patients with diabetes mellitus, and the impact of insulin and oral antidiabetic medication on relative fracture risk. Diabetologia 48:1292-1299

42. Johnston SS, Conner C, Aagren M, Ruiz K, Bouchard J (2012) Association between hypoglycaemic events and fall-related fractures in Medicare-covered patients with type 2 diabetes. Diabetes Obes Metab 14:634-643

43. Signorovitch JE, Macaulay D, Diener M et al (2012) Hypoglycaemia and accident risk in people with type 2 diabetes mellitus treated with non-insulin anti-diabetes drugs. Diabetes Obes Metab 15:335-341

44. Schwartz AV, Margolis KL, Sellmeyer DE et al (2012) Intensive glycemic control is not associated with fractures or falls in the ACCORD randomized trial. Diabetes Care 35:1525-1531

45. Gerstein HC, Miller ME, Byington RP et al (2008) Effects of intensive glucose lowering in type 2 diabetes. $\mathrm{N}$ Engl $\mathrm{J}$ Med 358:2545-2559

46. Li CI, Liu CS, Lin WY et al (2015) Glycated hemoglobin level and risk of hip fracture in older people with type 2 diabetes: a competing risk analysis of Taiwan Diabetes Cohort Study. J Bone Miner Res 30:1338-1346

47. Oei L, Zillikens MC, Dehghan A et al (2013) High bone mineral density and fracture risk in type 2 diabetes as skeletal complications of inadequate glucose control: the Rotterdam Study. Diabetes Care 36:1619-1628

48. Schneider AL, Williams EK, Brancati FL, Blecker S, Coresh J, Selvin E (2013) Diabetes and risk of fracture-related hospitalization: the Atherosclerosis Risk in Communities Study. Diabetes Care 36:1153-1158

49. Conway BN, Long DM, Figaro MK, May ME (2016) Glycemic control and fracture risk in elderly patients with diabetes. Diabetes Res Clin Pract 115:47-53

50. Ensrud KE, Ewing SK, Stone KL, Cauley JA, Bowman PJ, Cummings SR (2003) Intentional and unintentional weight loss increase bone loss and hip fracture risk in older women. J Am Geriatr Soc 51:1740-1747

51. Lipkin EW, Schwartz AV, Anderson AM et al (2014) The Look AHEAD Trial: bone loss at 4-year follow-up in type 2 diabetes. Diabetes Care 37:2822-2829

52. Johnson KC Lewis CE, Womack C et al. (2016) The effect of intentional weight loss on fracture risk in diabetics: results from the Look AHEAD Clinical Trial 65: LB-80 (Abstract)

53. Palermo A, D'Onofrio L, Eastell R, Schwartz AV, Pozzilli P, Napoli N (2015) Oral anti-diabetic drugs and fracture risk, cut to the bone: safe or dangerous? A narrative review. Osteoporos Int 26:2073-2089

54. Kahn SE, Zinman B, Lachin JM et al (2008) Rosiglitazone associated fractures in type 2 diabetes: an analysis from ADOPT. Diabetes Care 31:845-851

55. Loke YK, Singh S, Furberg CD (2009) Long-term use of thiazolidinediones and fractures in type 2 diabetes: a meta-analysis. CMAJ 180:32-39

56. Billington EO, Grey A, Bolland MJ (2015) The effect of thiazolidinediones on bone mineral density and bone turnover: systematic review and meta-analysis. Diabetologia 58:2238-2246

57. Schwartz AV, Chen H, Ambrosius WT et al (2015) Effects of TZD use and discontinuation on fracture rates in ACCORD Bone Study. J Clin Endocrinol Metab 100:4059-4066 
58. Monami M, Dicembrini I, Antenore A, Mannucci E (2011) Dipeptidyl peptidase-4 inhibitors and bone fractures: a metaanalysis of randomized clinical trials. Diabetes Care 34:2474 2476

59. Fu J, Zhu J, Hao Y, Guo C, Zhou Z (2016) Dipeptidyl peptidase-4 inhibitors and fracture risk: an updated meta-analysis of randomized clinical trials. Sci Rep 6:29104

60. Mamza J, Marlin C, Wang C, Chokkalingam K, Idris I (2016) DPP-4 inhibitor therapy and bone fractures in people with type 2 diabetes - a systematic review and meta-analysis. Diabetes Res Clin Pract 116:288-298

61. Su B, Sheng H, Zhang M et al (2014) Risk of bone fractures associated with glucagon-like peptide-1 receptor agonists' treatment: a meta-analysis of randomized controlled trials. Endocrine 48:107-115

62. Driessen JH, Henry RM, van Onzenoort HA et al (2015) Bone fracture risk is not associated with the use of glucagon-like peptide-1 receptor agonists: a population-based cohort analysis. Calcif Tissue Int 97:104-112

63. Driessen JH, van Onzenoort HA, Starup-Linde J et al (2015) Use of glucagon-like-peptide 1 receptor agonists and risk of fracture as compared to use of other anti-hyperglycemic drugs. Calcif Tissue Int 97:506-515

64. Taylor SI, Blau JE, Rother KI (2015) Possible adverse effects of SGLT2 inhibitors on bone. Lancet Diabetes Endocrinol 3:8-10

65. Ljunggren O, Bolinder J, Johansson L et al (2012) Dapagliflozin has no effect on markers of bone formation and resorption or bone mineral density in patients with inadequately controlled type 2 diabetes mellitus on metformin. Diabetes Obes Metab 14:990-999

66. Bilezikian JP, Watts NB, Usiskin K et al (2016) Evaluation of bone mineral density and bone biomarkers in patients with type 2 diabetes treated with canagliflozin. J Clin Endocrinol Metab 101:44-51

67. Watts NB, Bilezikian JP, Usiskin K et al (2016) Effects of canagliflozin on fracture risk in patients with type 2 diabetes mellitus. J Clin Endocrinol Metab 101:157-166

68. Zinman B, Wanner C, Lachin JM et al (2015) Empagliflozin, cardiovascular outcomes, and mortality in type 2 diabetes. $\mathrm{N}$ Engl J Med 373:2117-2128

69. Lapane KL, Yang S, Brown MJ, Jawahar R, Pagliasotti C, Rajpathak S (2013) Sulfonylureas and risk of falls and fractures: a systematic review. Drugs Aging 30:527-547

70. Napoli N, Strotmeyer ES, Ensrud KE et al (2014) Fracture risk in diabetic elderly men: the MrOS study. Diabetologia 57:2057-2065

71. Majumdar SR, Josse RG, Lin M, Eurich DT (2016) Does sitagliptin affect the rate of osteoporotic fractures in type 2 diabetes? Populationbased cohort study. J Clin Endocrinol Metab 101:1963-1969

72. Rajpathak SN, Fu C, Brodovicz KG, Engel SS, Lapane K (2015) Sulfonylurea use and risk of hip fractures among elderly men and women with type 2 diabetes. Drugs Aging 32:321-327

73. Colhoun HM, Livingstone SJ, Looker HC et al (2012) Hospitalised hip fracture risk with rosiglitazone and pioglitazone use compared with other glucose-lowering drugs. Diabetologia 55:2929-2937

74. Josse RG, Majumdar SR, Zheng Y, et al. (2016) Sitagliptin and risk of fractures in type 2 diabetes: results from the TECOS trial. Diabetes Obes Metab

75. Lapane KL, Jesdale BM, Dube CE, Pimentel CB, Rajpathak SN (2015) Sulfonylureas and risk of falls and fractures among nursing home residents with type 2 diabetes mellitus. Diabetes Res Clin Pract 109:411-419

76. Starup-Linde J, Gregersen S, Frost M, Vestergaard P (2016) Use of glucose-lowering drugs and risk of fracture in patients with type 2 diabetes. Bone 95:136-142

77. Monami M, Cresci B, Colombini A et al (2008) Bone fractures and hypoglycemic treatment in type 2 diabetic patients: a casecontrol study. Diabetes Care 31:199-203
78. Ahmed LA, Joakimsen RM, Berntsen GK, Fønnebø V, Schirmer $H$ (2006) Diabetes mellitus and the risk of non-vertebral fractures: the Tromsø study. Osteoporos Int 17:495-500

79. Mosenzon O, Wei C, Davidson J et al (2015) Incidence of fractures in patients with type 2 diabetes in the SAVOR-TIMI 53 trial. Diabetes Care 38:2142-2150

80. Thrailkill KM, Lumpkin CK Jr, Bunn RC, Kemp SF, Fowlkes JL (2005) Is insulin an anabolic agent in bone? Dissecting the diabetic bone for clues. Am J Physiol Endocrinol Metab 289:E735E745

81. Schwartz AV, Hillier TA, Sellmeyer DE et al (2002) Older women with diabetes have a higher risk of falls: a prospective study. Diabetes Care 25:1749-1754

82. American Diabetes Association (2017) Comprehensive medical evaluation and assessment of comorbidities. Diabetes Care 40(Suppl 1):S25-S32

83. Scragg R, Sowers M, Bell C, Third National Health and Nutrition Examination Survey (2004) Serum 25-hydroxyvitamin D, diabetes, and ethnicity in the Third National Health and Nutrition Examination Survey. Diabetes Care 27:2813-2818

84. Feng R, Li Y, Li G et al (2015) Lower serum $25(\mathrm{OH}) \mathrm{D}$ concentrations in type 1 diabetes: a meta-analysis. Diabetes Res Clin Pract 108:e71-e75

85. Institute of Medicine (2011) Dietary reference intakes for calcium and vitamin D. National Academies Press, Washington, DC

86. Avenell A, Mak JC, O'Connell D (2014) Vitamin D and vitamin D analogues for preventing fractures in post-menopausal women and older men. Cochrane Database Syst Rev, Issue 4, Art. no.: CD000227. doi:10.1002/14651858.CD000227.pub4

87. Manson JE, Brannon PM, Rosen CJ, Taylor CL (2016) Vitamin D deficiency — is there really a pandemic? N Engl J Med 375:1817_ 1820

88. Black DM, Rosen CJ (2016) Clinical practice. postmenopausal osteoporosis. N Engl J Med 374:254-262

89. Coe LM, Tekalur SA, Shu Y, Baumann MJ, McCabe LR (2015) Bisphosphonate treatment of type I diabetic mice prevents early bone loss but accentuates suppression of bone formation. J Cell Physiol 230:1944-1953

90. Keegan TH, Schwartz AV, Bauer DC, Sellmeyer DE, Kelsey JL (2004) Effect of alendronate on bone mineral density and biochemical markers of bone turnover in type 2 diabetic women: the fracture intervention trial. Diabetes Care 27:1547-1553

91. Inoue D, Muraoka R, Okazaki R, Nishizawa Y, Sugimoto T (2016) Efficacy and safety of risedronate in osteoporosis subjects with comorbid diabetes, hypertension, and/or dyslipidemia: a post hoc analysis of phase III trials conducted in Japan. Calcif Tissue Int 98:114-122

92. Johnell O, Kanis JA, Black DM et al (2004) Associations between baseline risk factors and vertebral fracture risk in the Multiple Outcomes of Raloxifene Evaluation (MORE) study. J Bone Miner Res 19:764-772

93. Ensrud KE, Stock JL, Barrett-Connor E et al (2008) Effects of raloxifene on fracture risk in postmenopausal women: the Raloxifene use for the heart trial. J Bone Miner Res 23:112-120

94. Vestergaard P, Rejnmark L, Mosekilde L (2011) Are antiresorptive drugs effective against fractures in patients with diabetes? Calcif Tissue Int 88:209-214

95. Abrahamsen B, Rubin KH, Eiken PA, Eastell R (2013) Characteristics of patients who suffer major osteoporotic fractures despite adhering to alendronate treatment: a National Prescription registry study. Osteoporos Int 24: 321-328

96. Schwartz AV, Pavo I, Alam J et al (2016) Teriparatide in patients with osteoporosis and type 2 diabetes. Bone 91:152-158 
97. Jennings LA, Auerbach AD, Maselli J, Pekow PS, Lindenauer PK, Lee SJ (2010) Missed opportunities for osteoporosis treatment in patients hospitalized for hip fracture. J Am Geriatr Soc 58:650-657

98. Khosla S, Burr D, Cauley J et al (2007) Bisphosphonateassociated osteonecrosis of the jaw: report of a task force of the American Society for Bone and Mineral Research. J Bone Miner Res 22:1479-1491
99. Shane E, Burr D, Abrahamsen B et al (2014) Atypical subtrochanteric and diaphyseal femoral fractures: second report of a task force of the american society for bone and mineral research. J Bone Miner Res 29:1-23

100. Dodson TB (2015) The frequency of medication-related osteonecrosis of the jaw and its associated risk factors. Oral Maxillofac Surg Clin North Am 27:509-516 